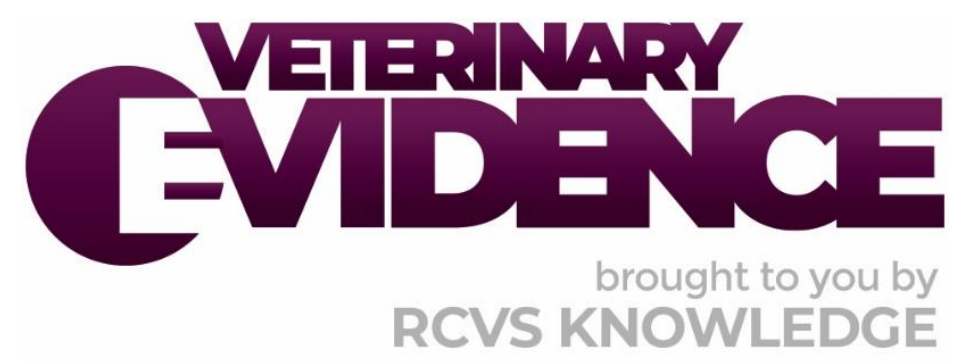

\title{
In dogs diagnosed with osteoarthritis, is meloxicam superior to carprofen for reducing patient discomfort?
}

\author{
A Knowledge Summary by
}

Lesca Monica Sofyan DVM student ${ }^{1^{*}}$

\footnotetext{
${ }^{1}$ Sydney School of Veterinary Science, The University of Sydney, Head Office JD Steward Building University of Sydney, NSW, 2006, Australia

*Corresponding Author (lesca.sofyan.xx@hotmail.com)
}

ISSN: 2396-9776

Published: 29 Jul 2020

in: Vol 5, Issue 3

DOI: $10.18849 / V E . V 513.288$

Reviewed by: Andy Morris (BSc(Hons) BVSc CertAVP(GSAS) MRCVS) and Robert Pettitt (BVSc PGCertLTHE DSAS (Orth) SFHEA FRCVS)

Next Review Date: 28 Aug 2021 


\section{KNOWLEDGE SUMMARY}

\section{PICO question}

In dogs diagnosed with osteoarthritis, is meloxicam superior to carprofen for reducing patient discomfort?

\section{Clinical bottom line}

\section{Category of research question}

\section{Treatment}

\section{The number and type of study designs reviewed}

Only two papers have compared the efficacy between meloxicam and carprofen in the treatment of dogs diagnosed with osteoarthritis. Both of the papers were clinical, prospective and randomised trials.

\section{Strength of evidence}

Weak

\section{Outcomes reported}

One randomised controlled clinical trial compared the level of efficacy between meloxicam and carprofen in reducing pain and discomfort in dogs diagnosed with osteoarthritis ${ }^{1}$. Orthopaedic surgeons found dogs treated with either meloxicam or carprofen showed significant improvement in ground reaction forces (GRF). The study emphasised that dogs treated with meloxicam had GRF values that returned to normal baseline values, with owners also commenting on gait improvement. This study however, had a low sample size, did not use a validated metrology instrument for assessment by owners and the data used to assess GRF was not conclusive on all parameters to favour meloxicam.

An additional study was evaluated but this also had very small case numbers, no control group and gave no detailed statistical analysis ${ }^{2}$. The paper descriptively suggests meloxicam to show a better response than carprofen but there was no scientific analysis or evidence to statistically support and validate this.

\section{Conclusion}

Both meloxicam and carprofen are validated as effective treatments for canine osteoarthritis but it cannot be suggested that meloxicam is superior to carprofen as the available evidence is weak. To accurately assess this, a future clinical study using validated metrology instruments, adequate sample sizes and proper statistical analysis is required.

\section{$\underline{\text { How to apply this evidence in practice }}$}

The application of evidence into practice should take into account multiple factors, not limited to: individual clinical expertise, patient's circumstances and owners' values, country, location or clinic where you work, the individual case in front of you, the availability of therapies and resources.

Knowledge Summaries are a resource to help reinforce or inform decision-making. They do not override the responsibility or judgement of the practitioner to do what is best for the animal in their care. 


\section{Clinical Scenario}

A 10-year-old Rottweiler cross has been diagnosed with canine osteoarthritis, specifically affecting the hip joints. His owner asks what the patient can be treated with to reduce discomfort and pain, particularly during walks. You recommend non-steroidal anti-inflammatory drugs (NSAIDs). You present the different types of NSAIDs available in your clinic, which are meloxicam and carprofen. The owner asks if one is superior to the other and whichever one that is, he will purchase. Ensuring that you are providing gold standard treatment, you want to ensure that you are providing an NSAID that has proven to be the most effective.

\section{The evidence}

Only one randomised controlled clinical trial compared the level of efficacy between meloxicam and carprofen in reducing pain and discomfort in dogs diagnosed with osteoarthritis. An additional study was evaluated but this had very small case numbers, no control group and gave no detailed statistical analysis. Both articles directly compared meloxicam and carprofen along with another treatment (either a nutraceutical or another NSAID) in reducing pain and discomfort for dogs diagnosed with osteoarthritis.

\section{Summary of the evidence}

Mariana et al. (2013)

Population: Recruitment

- Osteoarthritis registered cases were retrieved from two private veterinary hospitals and Faculty of Veterinary Medicine lasi

- $\quad$ Registered patients individually underwent a thorough clinical examination and a paraclinical test

\section{Criteria for eligibility and inclusion}

Patients were eligible and deemed to be appropriately diagnosed with osteoarthritis if they were found to experience the following osteoarticular inflammatory processes:

- Intense pain during movement

- Limping

- Sensitivity to pain when applied pressure

- Muscular rigidity

- Paravertebral tone decreased

- Impairment

\section{Criteria for exclusion and rejection}

- Recent operations (date and time range not stated)

- Limb or spinal fractures

- Females in gestation

- Diagnosed with a hepatic, renal or cardiac disorder

- Diseases or disorders that may interfere with the efficiency and safety of the treatment

- Ages ranged from 3-15 years

- Weight ranged from 6 to $15 \mathrm{~kg}$

- 21 males and nine females $(n=30)$ 


\begin{tabular}{|c|c|}
\hline Sample size: & 30 dogs $(n=30)$ \\
\hline Intervention details: & $\begin{array}{l}\text { Random allocation into treatment groups } \\
\text { - Each dog was randomly assigned to either a meloxicam, } \\
\text { carprofen or ketoprofen treatment group } \\
\text { - Meloxicam treatment group }=10 \text { subjects }(\mathrm{n}=10) \\
\text { - } \text { Ketoprofen treatment group }=10 \text { subjects }(\mathrm{n}=10) \\
\text { Administration of treatment } \\
\text { - Owners were instructed to provide treatment once a day (SID) } \\
\text { in the morning after breakfast for } 21 \text { days } \\
\text { Dosage of treatment } \\
\text { - Meloxicam at } 0.3 \mathrm{mg} / \mathrm{kg} \text { per body weight } \\
\text { - Carprofen at } 2.5 \mathrm{mg} / \mathrm{kg} \text { per body weight } \\
\text { - Ketoprofen at } 2 \mathrm{mg} / \mathrm{kg} \text { per body weight } \\
\text { Collection of faeces on days } 1 \text { and days } 21 \\
\text { - Faeces were collected for haemoccult tests }\end{array}$ \\
\hline Study design: & Clinical, randomised, blind study \\
\hline Outcome studied: & $\begin{array}{l}\text { Therapeutic efficiency of the NSAID treatment } \\
\text { Parameters of dogs assessed: } \\
\text { - Inflammation } \\
\text { - Pain intensity } \\
\text { - } \text { Any deformities or modifications } \\
\text { - General state modification } \\
\text { - Local hyperaemia } \\
\text { Numeric and visual analogic scale: } \\
\text { - Owners were required to examine and score the parameters } \\
\text { of the dog daily based } \\
\text { - Numeric scale ranked from } 0 \text { to } 3 \text { : } \\
\quad 0 \text { pain with general state modification; and } 3=\text { intense } \\
\quad \text { pain, immobilised and general state modification } \\
\text { - The visual analogic scale assisted with evaluating the intensity } \\
\text { of pain and inflammation } \\
\text { Clinician's assessment: } \\
\text { - On days } 5 \text {, } 10,15 \text { and } 21 \text {, clinicians also evaluated the } \\
\text { parameters of the dog according to the numeric and visual } \\
\text { analogic scale } \\
\text { Appearance of side effects and tolerability degree of NSAID } \\
\text { treatment } \\
\text { - Information on symptoms associated with gastrointestinal } \\
\text { localisation, sensitivity to abdominal palpation, weight loss, } \\
\text { queasiness, inappetence, hypersensitivity, oedema, sleeping }\end{array}$ \\
\hline
\end{tabular}




\begin{tabular}{|c|c|}
\hline & $\begin{array}{l}\text { disorders, high haemorrhagic risk, renal and hepatic disorders } \\
\text { were recorded } \\
\text { - Haemoccult tests were carried out to detect haemoglobin and } \\
\text { haemoglobin-haptoglobin in faeces collected from day } 1 \text { and } \\
\text { day } 21 \\
\text { - The haemoccult tests screened for potential digestive } \\
\text { haemorrhage that may occur in intoxications or long-term } \\
\text { therapy (7-10 days) with NSAIDs }\end{array}$ \\
\hline $\begin{array}{l}\text { Main findings: } \\
\text { (relevant to PICO question): }\end{array}$ & $\begin{array}{l}\text { - At day } 21 \text {, approximately } 93 \% \text { of the total subjects displayed } \\
\text { total remission of pain and inflammation associated with } \\
\text { osteoarticular disorders since administered to a treatment } \\
\text { group } \\
\text { - Meloxicam treatment group had the highest positive response } \\
\text { to diminished pain and inflammation (90\%) followed by } \\
\text { ketoprofen ( } 75 \%) \text { and carprofen }(68 \%) \text {. This finding was not } \\
\text { significant }\end{array}$ \\
\hline Limitations: & $\begin{array}{l}\text { - Small sample size } \\
\text { - Subjective assessment by owners } \\
\text { - No power analysis or statistical analysis was mentioned or } \\
\text { performed to obtain a p-value. The authors do comment } \\
\text { there was no statistical difference between treatment groups } \\
\text { but give no details of the statistics performed } \\
\text { - Poor inclusion criteria and eligibility - no radiographic } \\
\text { evaluation alongside orthopaedic examination by a board } \\
\text { registered specialist } \\
\text { - Treatment doses were not in line with current } \\
\text { recommendations }\end{array}$ \\
\hline
\end{tabular}

Moreau et al. (2003)

Population: Recruitment

- Medical files of the Université de Montréal teaching hospital

- Newspaper advertisement

Criteria for eligibility and inclusion

- Canines over 18-months-old and weighed over $20 \mathrm{~kg}$

- Provided radiographic evidence of osteoarthritis in one or two elbows, one or two hips or one or two stifle joints

- Osteoarthritis pathology caused by lameness determined by complete orthopaedic examination

- Canines with a rupture due to cranial cruciate ligament that had been surgically repaired over a year or diagnosed over a year without surgical correction

\section{Criteria for rejection and exclusion}

- Canines with abnormalities in both the forelimb and hindlimb

- Canines on concurrent treatment for osteoarthritis

- Pregnant bitches as reports have highlighted hypersensitivity reactions to NSAIDs 


\begin{tabular}{|c|c|}
\hline & $\begin{array}{l}\text { - Canines with a neurological or musculoskeletal pathology } \\
\text { other than osteoarthritis that had undergone orthopaedic } \\
\text { surgery within the same year } \\
\text { Control Group } \\
\text { - Normal and breed-matched dogs determined by orthopaedic, } \\
\text { radiographical and neurological examination }\end{array}$ \\
\hline Sample size: & 71 dogs diagnosed with osteoarthritis $(n=71)$ \\
\hline Intervention details: & 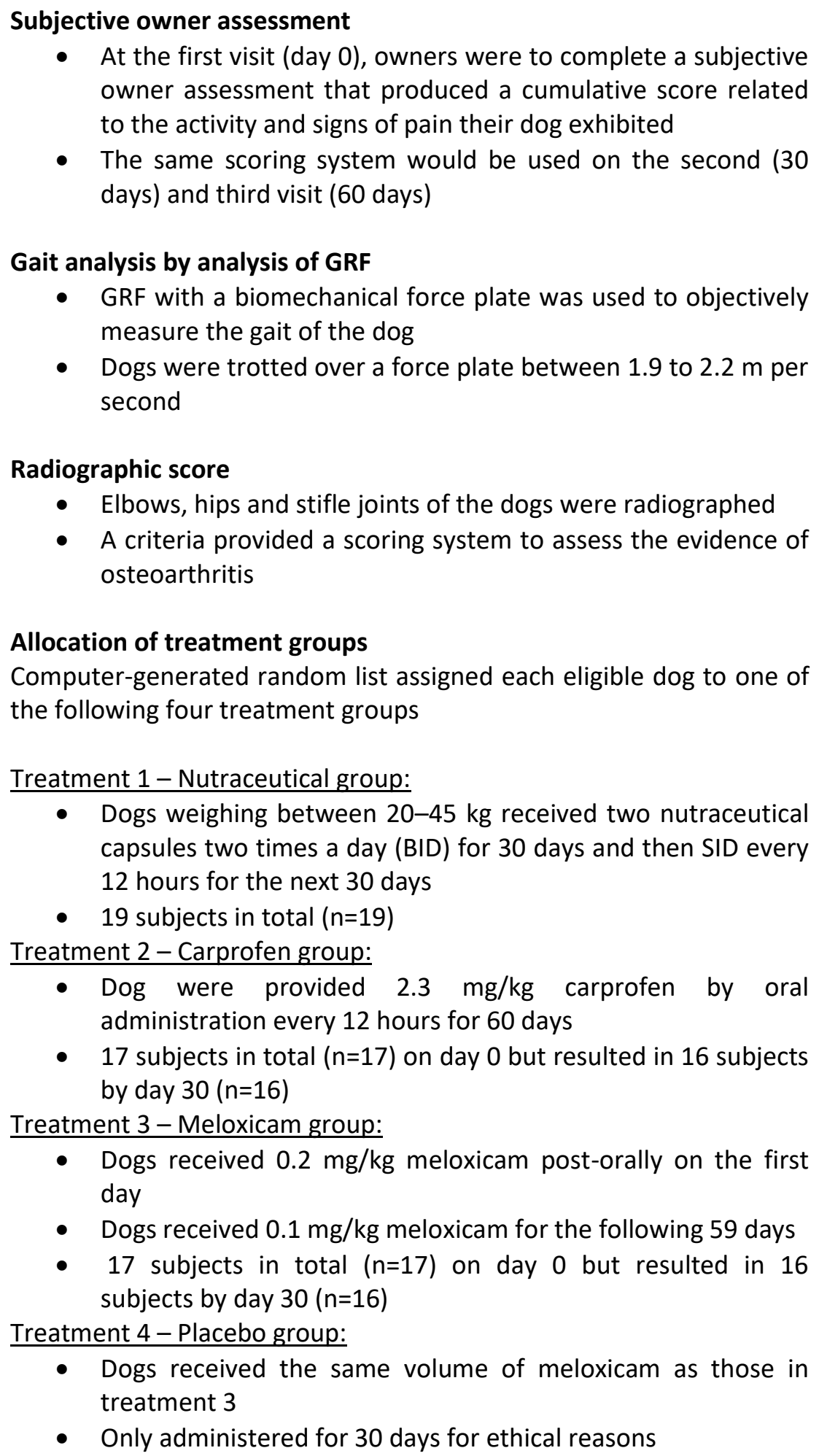 \\
\hline
\end{tabular}




\begin{tabular}{|c|c|}
\hline & $\begin{array}{l}\text { - } 18 \text { subjects in total ( } \mathrm{n}=18 \text { ) on day } 0 \text { but resulted in } 17 \text { subjects } \\
\text { by day } 30 \text { ( } \mathrm{n}=17 \text { ) } \\
\text { Subjective clinical evaluation by a veterinary orthopaedic surgeon on } \\
\text { day } 0,30 \text { and } 60 \\
\text { - One of two veterinary orthopaedic surgeons visually } \\
\text { examined the gait of the patients } \\
\text { - If osteoarthritis was present in more than one joint, only the } \\
\text { most affected was clinically evaluated } \\
\text { - The two veterinary orthopaedic surgeons were not aware of } \\
\text { the GRF or the treatment assigned to the dogs } \\
\text { Blood and faecal analysis } \\
\text { - Blood samples from each patient were sampled to provide } \\
\text { haematology and biochemical results as a general pre-health } \\
\text { check screen prior to continuation in the study } \\
\text { - Haematology and biochemistry values were repeated on days } \\
30 \text { and } 60 \text { to ensure no adverse reactions or side effects were } \\
\text { encountered } \\
\text { Verification that treatment was provided } \\
\text { - On days } 30 \text { and } 60 \text { post-treatment, owners were to bring the } \\
\text { unused/unnamed product to verify the dogs indeed received } \\
\text { the treatment }\end{array}$ \\
\hline Study design: & Clinical, prospective, randomised double-blind study \\
\hline Outcome studied: & $\begin{array}{l}\text { On the first day of the study followed by } 30 \text { days and } 60 \text { days post- } \\
\text { treatment, the following were analysed: } \\
\text { - Subjective evaluation provided by owners of the patient } \\
\text { - Subjective clinical evaluation by a veterinary orthopaedic } \\
\text { surgeon } \\
\text { - Objective gait analysis of dogs using a GFR }\end{array}$ \\
\hline $\begin{array}{l}\text { Main findings: } \\
\text { (relevant to PICO question): }\end{array}$ & $\begin{array}{l}\text { - Only owners of the dogs in the meloxicam group claimed } \\
\text { there had been improvement, appearing to alleviate the } \\
\text { arthritic lameness of the dog and allow it to resume to normal } \\
\text { daily activities } \\
\text { - Subjective orthopaedic assessments revealed both carprofen } \\
\text { and meloxicam improved the mobility of patients by day } 30 \\
\text { and day } 60 \\
\text { - Gait profiles/GRF values compared by the Wilcoxon rank-sum } \\
\text { test at a significance level of } 5 \%^{2} \\
\text { - GRF improved in response to meloxicam and carprofen } \\
\text { treatment }(P<0.017) \\
\text { On days } 60 \text {, dogs treated with meloxicam had craniocaudal } \\
\text { GRF considered to be of normal value }(P<0.05) \text { whilst those } \\
\text { treated with carprofen had steady, declining GRF ( } P>0.05) \\
\text { - Treatment with meloxicam was found to be the most } \\
\text { appropriate and improved for canines with a severe and } \\
\text { inflammatory process, efficacy in improving the dog's gait to } \\
\text { resume to normal life and have an absence of side effects }\end{array}$ \\
\hline
\end{tabular}




\begin{tabular}{|l|l|}
\hline Limitations: & $\begin{array}{l}\text { - Small sample size } \\
\text { - }\end{array}$ \\
& $\begin{array}{l}\text { Daily mobility level and activity of the dogs were not } \\
\text { described which may have influenced the progression of the } \\
\text { treatment }\end{array}$ \\
- & $\begin{array}{l}\text { Subjective assessment by owners and veterinary orthopaedic } \\
\text { surgeons } \\
\text { Validated metrology instruments for measuring response to } \\
\text { osteoarthritis treatments/assessment of chronic pain not } \\
\text { available at time of publication }\end{array}$ \\
\hline
\end{tabular}

\section{Appraisal, application and reflection}

Both studies obtained observational evaluations from owners regarding their dog's mobility and gait during treatment although, this qualitative approach was more predominant in the study by Mariana et al. (2013). Whilst this is beneficial in providing primary insight on owner's experiences, it does possess weaknesses. Qualitative evaluations are not narrowly focused on a specific question ${ }^{3}$. The observations made by owners are not controlled in a clinical setting and thus, selective bias may be introduced into the study as an owner may favour one NSAID over another (e.g. meloxicam over carprofen). Furthermore, participants may misinterpret criteria and guidelines and thus deliver incorrect or vague answers. Metrology instrument testing for canine osteoarthritis are now available and have been clinically validated to effectively assess the quality of life and locomotive function in dogs with orthopaedic related disorders ${ }^{4}$. One of the instruments that may have been useful for Mariana et al. (2013) and for future related studies is the Canine Orthopaedic Index (COI) ${ }^{4}$. The COI assesses the following four domains - stiffness, function, gait and quality of life for patients diagnosed with osteoarthritis or related orthopaedic disorders. The outcome provides a quantifiable assessment that clinicians and researchers can use to assess the efficacy of treatment provided.

The sample sizes in both studies were considerably small. Both studies did not provide details on how sample size was determined for it to be considered appropriate and adequate for clinical research. In validated scientific research and clinical trials, sample size should be determined from a power analysis. Appropriate sample sizes are essential in providing a true representation of an underlying population and ensuring that the clinical question proposed allows for a valid statistical analysis ${ }^{5}$. Inadequate sized studies are underpowered and may lead to statistical error and invalid conclusions.

Blinding is an important and distinct feature in randomised controlled trials to reduce selection bias from affecting results, which both studies $\mathrm{did}^{1,2,6,7}$. Patients and evaluators assigned to a treatment with knowledge and no concealment may deliberately select to disapprove or approve a treatment based on personal beliefs and influential factors ${ }^{6,7}$. Clinically, it is common for practitioners to favour a particular therapeutic drug over another for certain procedures. The lack of a control group in the Mariana et al. (2013) study also meant there was no baseline to compare and assess the efficacy of the intervention (i.e. meloxicam or carprofen) that is essential in clinical trials ${ }^{5,6}$.

Statistical analysis is a crucial foundation in evidence-based clinical practice and should be implemented in all clinical trials and research ${ }^{8}$. The small sample size, lack of statistical analysis and poor eligibility criteria in the study by Mariana et al. (2013) may have meant that the results retrieved from the study were largely due to chance, thus limiting valid conclusions to be drawn. The application of statistical analysis (e.g. use of p-values and confidence intervals) aids in building a solid and sound evidence to ensure that the clinical courses and treatments tested are most likely to follow and have the same result ${ }^{8}$.

Moreau et al.'s (2003) application of analysing GFR strengthened the findings of the study. Analysis of GFR is a non-invasive method and objective measurement of gait evaluation ${ }^{9,10}$. It accurately assesses between normal and abnormal gait, identifying characteristic features in gait abnormalities ${ }^{9}$. The findings of the GFR in Moreau 
et al.'s study (2003) was accompanied with the owner's assessment of their dog's mobility, representing a quantitative and qualitative approach to the study and orthopaedic surgeon assessment. The combined use of a quantitative and qualitative approach as used in Moreau et al.'s (2003) study is advocated in clinical trials as it neutralises flaws that may be present in one methodology and strengthens and validates results9,10,11. The results of the GFR can be corresponded to the owner's assessment in regard to treatment response.

Consistency was adhered to in both methodological approaches where there was no note on potential external interferences (e.g. weight loss, hydrotherapy, physiotherapy, chondroitin sulphate injections) that may have potentially skewed the results of the studies.

An additional finding in the Moreau et al. (2003) study worth noting was a case whereby a patient was diagnosed with toxic idiosyncratic hepatitis to the carprofen treatment group. Side effects from the use of long-term NSAIDs are a significant concern amongst owners and small animal practitioners. Mariana et al. (2013) claimed meloxicam was better tolerated than carprofen due to the differing pathogenesis of the two treatments, as meloxicam is a COX-2 inhibitor and carprofen is a COX-1 inhibitor ${ }^{2}$. However, this is questionable as current evidence recognises carprofen preferentially inhibiting the COX-2 enzyme pathway ${ }^{9}$.

Despite the finding in Moreau et al. (2013) study, all dosages must be adjusted or lowered to the safest level when treating any case of osteoarticular inflammation. The dose range of $0.3 \mathrm{mg} / \mathrm{kg}$ for meloxicam used in the Mariana et al. (2013) study is actually higher than what is recommended ${ }^{9}$. The recommended meloxicam initial dose is $0.2 \mathrm{mg} / \mathrm{kg}$ followed by a maintenance dose of $0.1 \mathrm{mg} / \mathrm{kg}$ post-orally (PO) every 24 hours ${ }^{9}$. In MonteirSteagall et al.'s (2013) systematic review of the drug induced adverse effects found variable results on the number of common adverse effects encountered from carprofen and meloxicam ${ }^{13}$. Across the high strength of evidence, both meloxicam and carprofen induced adverse side effects including vomiting and diarrhoea as the two most common, as well as anorexia, lethargy, diarrhoea and melena ${ }^{13}$. Meloxicam is available in both tablet and liquid formulation whilst carprofen is available only in tablet form. Dogs that do not tolerate well with tablet administration may be provided the alternative of the meloxicam liquid formulation, but this may be limited if unwanted side effects have been experienced with dogs on meloxicam. Therefore, whether practitioners and clients choose to prescribe carprofen and meloxicam for managing osteoarthritis, the health parameters and status of the patient on the treatment should be independently and regularly monitored to detect early unwanted side effects.

Both studies found patients diagnosed with osteoarthritis treated with either meloxicam or carprofen indeed improved articular motility. However, the absence of validated metrology instruments, poor eligibility and inclusion criteria, lack of statistical analysis and poor sample sizes does mean the studies are not universally and scientifically valid to conclude that the benefits of meloxicam are superior to carprofen.

The two studies are nonetheless good foundations for a much wider and future study, such as a prospective randomised controlled trial with adequate population sizes, proper statistical analysis and validated metrology instruments to potentially assess the superiority of one NSAID to another.

Meloxicam or carprofen evidently improve patients with osteoarthritis but the evidence to scientifically conclude that meloxicam is superior to carprofen is weak. The selection of an NSAID by small animal practitioners for patients diagnosed with osteoarthritis should thus be selected on other variables such as suitability for the patient signalment (e.g. dosage levels, history of side effects if previously medicated on an NSAID), owner's satisfaction (e.g. tablet vs liquid form, cost) and veterinarian's discretion. 


\begin{tabular}{|c|c|}
\hline $\begin{array}{r}\text { Databases searched and dates } \\
\text { covered: }\end{array}$ & $\begin{array}{l}\text { PubMed database accessed via the NCBI platform (1910-2019) } \\
\text { CAB Abstracts database via Web of Science (1973-2019) }\end{array}$ \\
\hline Search terms: & $\begin{array}{l}\text { ((((osteoarthritis OR arthritis OR OA OR osteo-arthritis)) AND (canine } \\
\text { OR canines OR dogs OR dogs)) AND (Meloxicam OR Metacam OR } \\
\text { Loxicom OR Loxioral OR Melonex OR Meloxidy OR Mobic OR Mobicox } \\
\text { OR Orocam)) AND (Carprofen OR Rimadyl OR Novox) }\end{array}$ \\
\hline Dates searches performed: & 28 Aug 2019 \\
\hline
\end{tabular}

\section{Exclusion / Inclusion Criteria}

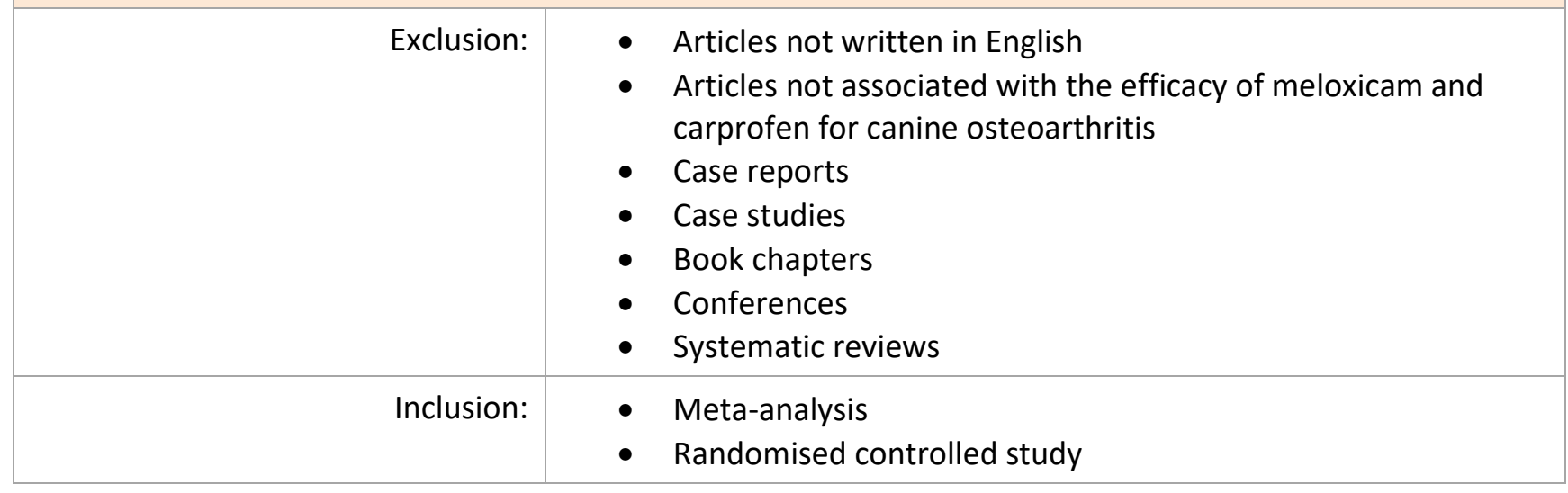

\begin{tabular}{|c|c|c|c|c|c|c|c|c|}
\hline \multicolumn{9}{|c|}{ Search Outcome } \\
\hline Database & $\begin{array}{l}\text { Number } \\
\text { of } \\
\text { results }\end{array}$ & $\begin{array}{c}\text { Excluded } \\
- \\
\text { systematic } \\
\text { reviews }\end{array}$ & $\begin{array}{l}\text { Excluded } \\
\text { - did not } \\
\text { relate } \\
\text { directly } \\
\text { to the } \\
\text { factors of } \\
\text { PICO }\end{array}$ & $\begin{array}{l}\text { Excluded } \\
\text { - case } \\
\text { reports } \\
\text { and } \\
\text { studies }\end{array}$ & $\begin{array}{l}\text { Excluded } \\
\text { - book } \\
\text { chapters }\end{array}$ & $\begin{array}{c}\text { Excluded } \\
- \\
\text { not } \\
\text { written } \\
\text { in } \\
\text { English }\end{array}$ & $\begin{array}{l}\text { Excluded - } \\
\text { conferences }\end{array}$ & $\begin{array}{c}\text { Total } \\
\text { relevant } \\
\text { papers }\end{array}$ \\
\hline PubMed & 9 & 3 & 5 & 0 & 0 & 0 & 0 & 1 \\
\hline $\begin{array}{l}\text { CAB } \\
\text { Abstracts }\end{array}$ & 19 & 1 & 13 & 0 & 0 & 1 & 2 & 2 \\
\hline Total relev & pape & en dupli & emoved & & & & & 2 \\
\hline
\end{tabular}




\section{CONFLICT OF INTEREST}

The author declares no conflicts of interest.

However, the author would like to greatly thank Bridget Sheppard and Jennifer Morris for their assistance and guidance in this publication, the reviewers (Clare Boulton, Andy Morris and Robert Pettitt) and the team of the journal for providing this opportunity.

Lastly but not least, the author would like to dedicate this paper to Matt Fotheringham and in memory of Sefton Fotheringham for inspiring the clinical question to hopefully aid future clients and patients alike.

\section{REFERENCES}

1. Moreau, M., Dupuis, J., Bonneau, N. H. \& Desnoyers, M. (2003). Clinical evaluation of a nutraceutical, carprofen and meloxicam for the treatment of dogs with osteoarthritis. Veterinary Record, 152(11): 323-329. DOI: http://dx.doi.org/10.1136/vr.152.11.323

2. Mariana, G., Valentin, N., Raluca, M. \& Hritcu, D-L. (2013). Comparative evaluation on the efficiency and tolerability of three NSAIDs used in locomotive osteoarticular inflammations in dog. Scholars Journals of Agriculture and Veterinary Sciences. 56: 274-282.

3. Choy, L. T. (2014). The Strengths and Weaknesses of Research Methodology: Comparison and Complimentary between Qualitative and Quantitative Approaches. Journal of Humanlties and Soclal Science, 19(4): 99-104. DOI: http://dx.doi.org/9790/0837-194399104

4. Cook, J. (2014). Canine Orthopedic Outcome Measures Program: Where Are We Now? Veterinary Surgery, 43(3): 229-231. DOI: https://doi.org/10.1111/j.1532-950X.2014.12167.x

5. Suresh, K. P. \& Chandrashekara, S. (2012). Sample size estimation and power analysis for clinical research studies. Journal of Human Reproductive Science, 5(1): 7-13. DOI: https://doi.org/4103/0974$\underline{1208.97779}$

6. Bang, H., Ni, L. \& Clarence, E. D. (2004). Assessment of blinding in clinical trials. Controlled Clinical Trials, 25(2): 143-156. DOI: https://doi.org/10.1016/j.cct.2003.10.016

7. Juni, P., Altman, D.G. \& Egger, M. (2001). Assessing the quality of controlled clinical trials. BMJ, 323: 42-46. DOI: https://doi.org/10.1136/bmj.323.7303.42

8. Barkan, H. (2015). Statistics in clinical research: Important considerations. Annals of Cardiac Anaesthesia, 18(1): 74-82. DOI: http://dx.doi.org/10.4103/0971-9784.148325

9. Ramsey, I. (2017). Small Animal Formulary $9^{\text {th }}$ Edition - Part A: Canine and Feline. 59.

10. Anderson, M. A. \& Mann, F. A. (1994). Force plate analysis: a non-invasive tool for gait evaluation. Compendium on Continuing Education for the Practicing Veterinarian, 16: 857-866.

11. McLaughlin, R. M. (2001). Kinetic and Kinematic Gait Analysis in Dogs. Veterinary Clinics of North America: Small Animal Practice, 31(1): 193-201. DOI: https://doi.org/10,.1016/S0195-5616(01)50045$\underline{5}$

12. Hussein, A. (2009). The Use of Triangulation in Social Sciences Research: Can qualitative and quantitative methods be combined? Journal of Social Work Practice, 01-12.

13. Monteiro-Steagall, B. P., Steagall P. M. V. \& Lascelles, B. D. X. (2013). Systemic Review of Nonsteroidal Anti-Inflammatory Drug-Induced Adverse Effects in Dogs.Journal of Veterinary Internal Medicine, 27(5): 1011-1019. DOI: http://doi.org/10.1111/ivim.12127 


\section{EVIIDEFeE

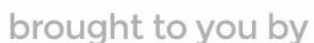 \\ RCVS KNOWLEDGE}

\section{Intellectual Property Rights}

Authors of Knowledge Summaries submitted to RCVS Knowledge for publication will retain copyright in their work, and will be required to grant RCVS Knowledge a non-exclusive license of the rights of copyright in the materials including but not limited to the right to publish, re-

publish, transmit, sell, distribute and otherwise use the materials in all languages and all media throughout the world, and to license or permit others to do so.

\section{Disclaimer}

Knowledge Summaries are a peer-reviewed article type which aims to answer a clinical question based on the best available current evidence. It does not override the responsibility

of the practitioner. Informed decisions should be made by considering such factors as individual clinical expertise and judgement along with patient's circumstances and owners' values. Knowledge Summaries are a resource to help inform and any opinions expressed within the Knowledge Summaries are the author's own and do not necessarily reflect the view of the RCVS Knowledge. Authors are responsible for the accuracy of the content. While the

Editor and Publisher believe that all content herein are in accord with current recommendations and practice at the time of publication, they accept no legal responsibility

for any errors or omissions, and make no warranty, express or implied, with respect to material contained within.

For further information please refer to our Terms of Use.

RCVS Knowledge is the independent charity associated with the Royal College of Veterinary Surgeons (RCVS). Our ambition is to become a global intermediary for evidence based veterinary knowledge by providing access to information

that is of immediate value to practicing veterinary professionals and directly contributes to evidence based clinical decision-making.

https://www.veterinaryevidence.org/

RCVS Knowledge is a registered Charity No. 230886.

Registered as a Company limited by guarantee in England and Wales No. 598443.

Registered Office: Belgravia House, 62-64 Horseferry Road, London SW1P 2AF

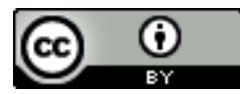

This work is licensed under a Creative Commons Attribution 4.0 International License 